\title{
Tooth-Coding Systems in the Clinical Dental Setting
}

\author{
Edward F. Harris* \\ Department of Orthodontics, University of Tennessee, Memphis, Tennessee
}

ABSTRACT Clinical dentists have developed a variety of tooth-coding systems for efficiently recording a patient's dental status. The coding systems may not be self-evident to dental anthropologists lacking dental training. The purpose of this note is to review the tooth designation systems currently in common use. The nature of the charting systems and brief historical origins of three systems are reviewed, namely (1) the

Dental anthropologists-building on classic anatomical nomenclature-have a precise lexicon of terms for designating specific teeth. There is, for example, no confusion when describing a human's "permanent maxillary right central incisor." Such labels are, however, lengthy and cumbersome, no more so than in the dental clinical setting where a dentist needs to expeditiously document voluminous details on numerous patients in a concise manner (Schwartz and Stege, 1977).

The practical need for conciseness, precision and brevity has led clinicians to develop a variety of tooth coding systems, some of which are intuitive while others are refractory without some clues. The purpose of this note is to delineate the common clinical systems of tooth coding in order to familiarize dental anthropologists with the clinical nomenclature.

\section{Permanent dentition}

It is common knowledge that the adult human dentition consists of 32 teeth arrayed into four morphological classes in each quadrant (e.g., Todd, 1918; LeGros Clark, 1959). This leads to the dental formula

$$
\mathrm{I} \frac{2}{2} \mathrm{C} \frac{1}{1} \mathrm{P} \frac{2}{2} \mathrm{M} \frac{3}{3} \quad \text { or, simply, } \frac{2123}{2123}
$$

which is a symbolic denotation that there normally are 2 incisors, 1 canine, 2 premolars, and 3 molars in each of the four quadrants of the mouth. The etymologies of these dental terms are all from the Latin. Incisor (L. incidere $=$ to cut into) alludes to the incisors' function of incising and nipping; incisors are the "cutting teeth." Canines (L. canis $=\mathrm{dog}$, hound) derives from the prominent, well-developed teeth in the family Canidae (dogs), though their value for prehension has been considerably diminished in humans, where these teeth function essentially as incisors. Most clinical dentists use the term cuspid in place of canine, since
Zsigmondy-Palmer system that is becoming largely of historical interest, (2) the Universal system that is common in the United States, and (3) the FDI two-digit system that has been adapted throughout the rest of the world. Use of these three systems is described for the permanent and primary dentitions. Dental Anthropology 2005;18(2):43-49.

these teeth normally consist of one large primary cusp. "Premolars" merely recognizes the anatomical position of these teeth in front of the molars. Clinicians commonly use the term bicuspid in place of premolar, since these teeth commonly (but certainly not always) possess two cusps (cf. Kraus and Furr, 1953). Molars (L. molaris $=$ millstone) refers to the grinding, triturating function of these teeth with their substantial occlusal surfaces.

\section{Zsigmondy-Palmer system}

The most popular system of tooth designation for much of the 20th century was developed by the Viennese dentist Adolph Zsigmondy (Zsigmondy, 1861, 1874). He broke with tradition, substituting numbers for the eight teeth in each quadrant in place of the lengthy Latin names in use to that time (Schwartz and Stege, 1977; Peck and Peck, 1993). The correspondence is:

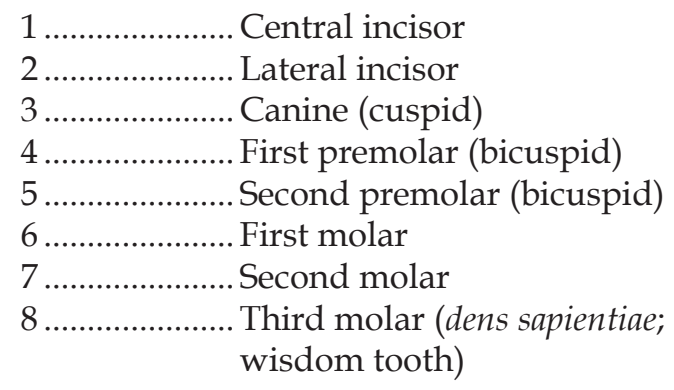

Zsigmondy combined his tooth numbering system with a graphical device to specify the quadrant of the mouth. An L-shaped mark $(L)$ was used, with the

*Correspondence to: Edward F. Harris, Department of Orthodontics, College of Dentistry, The Health Science Center, 875 Union Avenue, University of Tennessee, Memphis, TN 38163.

E-mail: eharris@utmem.edu 


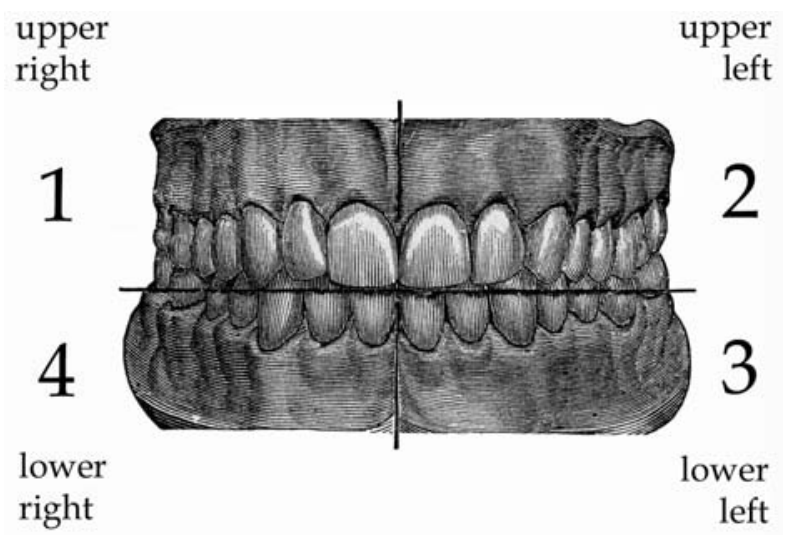

Fig. 1. Facsimile of a diagram by Palmer (1891) showing the division of the dentition into four quadrants. The vertical and horizontal line segments are used in this charting method to specify a tooth's quadrant. Facing the patient, as here, the quadrants are numbered clockwise from the upper left of the figure, so the patient's quadrants are (1) upper right, (2) upper left, (3) lower left, and (4) lower right.

vertical line segment being the subject's midline and the horizontal segment his occlusal plane that separates the upper and lower arcades. The clinician could, then, easily code a specific tooth, such as the lower left canine

$\sqrt{3}$ or the upper right first molar 6 . Confusion is pretty much limited to the novitiate's need to remember that the codes refer to the patient's left or right side.

History then becomes a bit conflicted because the Ohio dentist Corydon Palmer (Palmer, 1870, 1891) argued for his independent invention of the same coding system. Palmer contended that the natural division of the dentition into quadrants was a well-known, obvious device (Fig. 1). Indeed, Palmer was quite testy in his
1891 paper that he be given all credit for the scheme's development (Fig. 2). The quadrant is denoted by the shape of the symbol, like $\Gamma$ for mandibular left, and the tooth position is numbered from 1 (central incisor) through 8 (third molar). The scheme has a naturalness and simplicity such that independent invention seems probable. In any event, most American dentists have been taught the notation as being Palmer's (though also termed the "quadrant system" by some; Sharma and Wadhwa, 1977). The Palmer system also has been labeled the "angular system" and the "grid system" because of the horizontal and vertical line segments that denote the tooth's quadrant.

The obvious down-side of the Zsigmondy-Palmer notation is that, while it is easy to sketch the tooth codes in a patient's record, it is tedious to type or verbalize them. For instance, there is no word for the symbol $\lceil$ or \rfloor . Gustafson (1966), O'Connor (1983) and others have commented that Palmer's angle symbol denoting side and arch probably was the system's undoing. While it is no effort at all to jot down $\lceil 5$ or 7 in a patient's record, there is no natural analog for $\sqrt{3}$ with an embedded digit on a typewriter or word-processor. Indeed, it was the need to computerize the dental recording system that marshaled-in the FDI system-and incidentally promoted the use of the Universal system in the United States. Coding a tooth numerically, as \#16 or 28 , lends itself to word processing.

\section{Desiderata}

There are a few other items of note that developed contemporaneous with Zsigmondy and Palmer but do not warrant full-blown descriptions here. The Latin terms
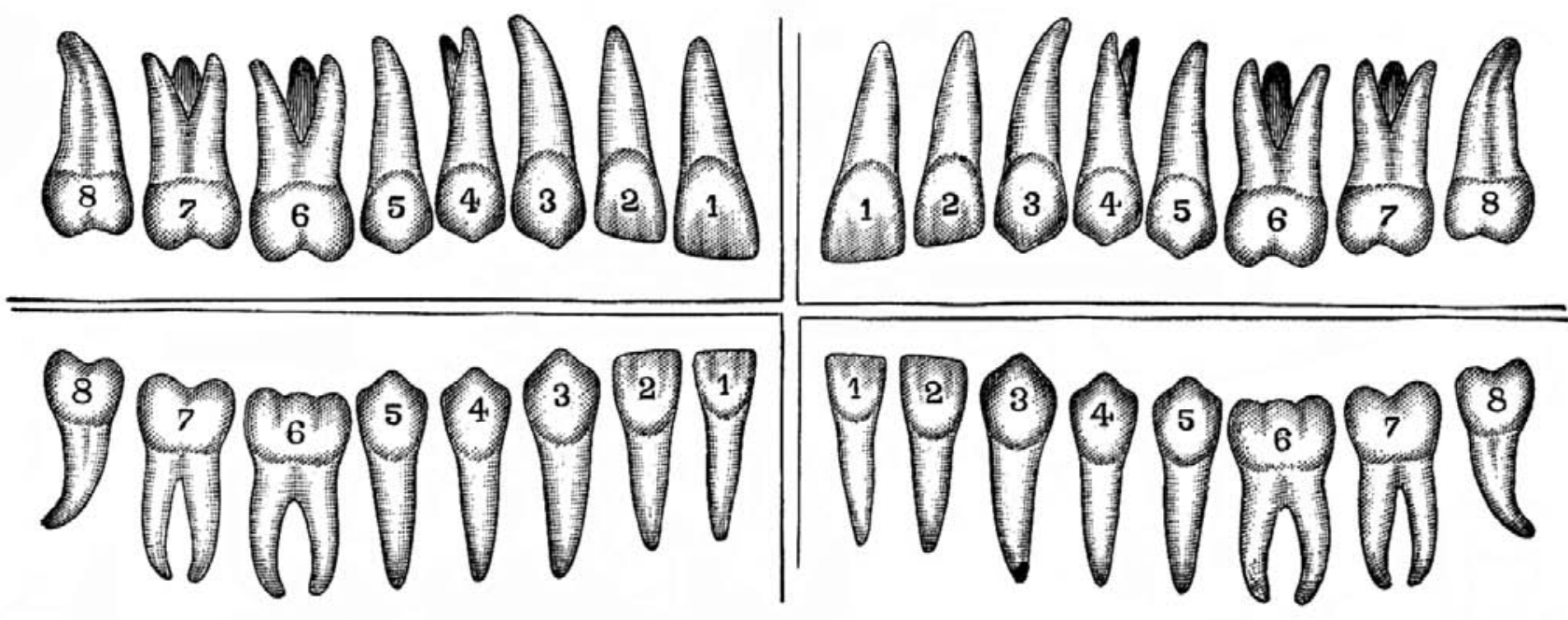

Fig 2. The Zsigmondy-Palmer tooth designation system, where lines define the four quadrants and the teeth are numbered from 1 to 8 in each quadrant (modified from Palmer, 1891). 


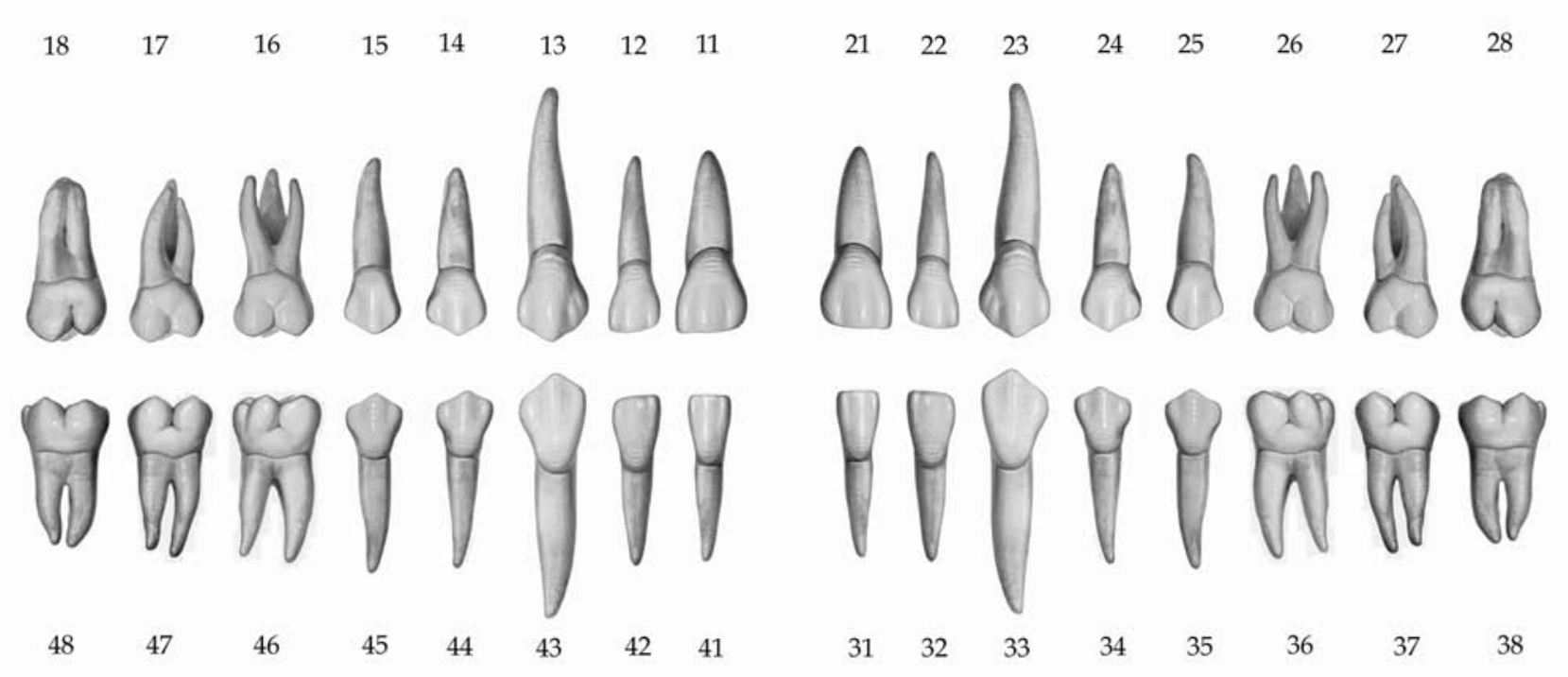

Fig. 3. The FDI two-digit scheme for tooth designations of the permanent dentition. The view is oriented as if you are looking at the subject, so the person's right side (quadrants 1 and 4) are to the left of the page.

superiore (sup.) and inferiore (inf.) will be encountered in the older literature, referring to the maxillary and mandiblar jaws, respectively. Likewise, the Latin words dextral (dext.) and sinistral (sin.) commonly were used to denote a tooth in the right or left arcade, respectively. So, for example, de Terra (1905:5) uses the code "I1 sup. sin." to denote the maxillary left I1 (central incisor).

Also, Haderup's (1891) tooth designation system experienced popularity for some decades after its introduction. In place of Zsigmondy's angle (e.g., $\Gamma)$, Haderup used a plus sign $(+)$ to denote a maxillary tooth and a minus sign (-) for a mandibular tooth, and the sign was placed mesial to the tooth being referred to, so a right upper second molar would be $7+$ and a left lower first premolar would be -4 .

\section{FDI system}

Dentists throughout the world-notably excepting the United States-now use the FDI two-digit system (Fédération Dentaire Internationale). This scheme was developed by a "Special Committee on Uniform Dental Recording" and passed as a resolution of the FDI General Assembly at its 1970 meeting in Bucharest, Romania (Keiser-Nielsen, 1971a,b,c). While the FDI labeled this the "Two-Digit System," it is more commonly referred to as the FDI system. It is useful to consider the five crite-

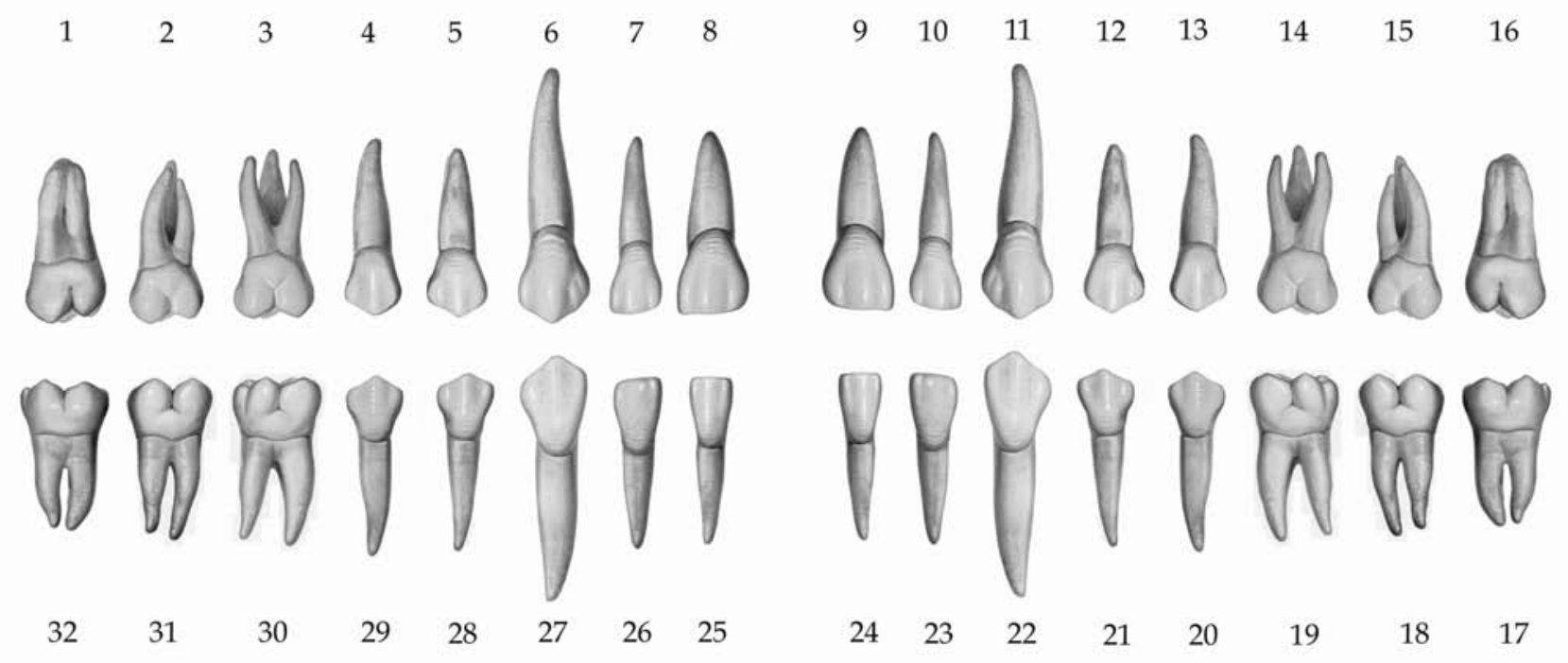

Fig. 4. The Universal scheme for tooth designations of the permanent dentition. 


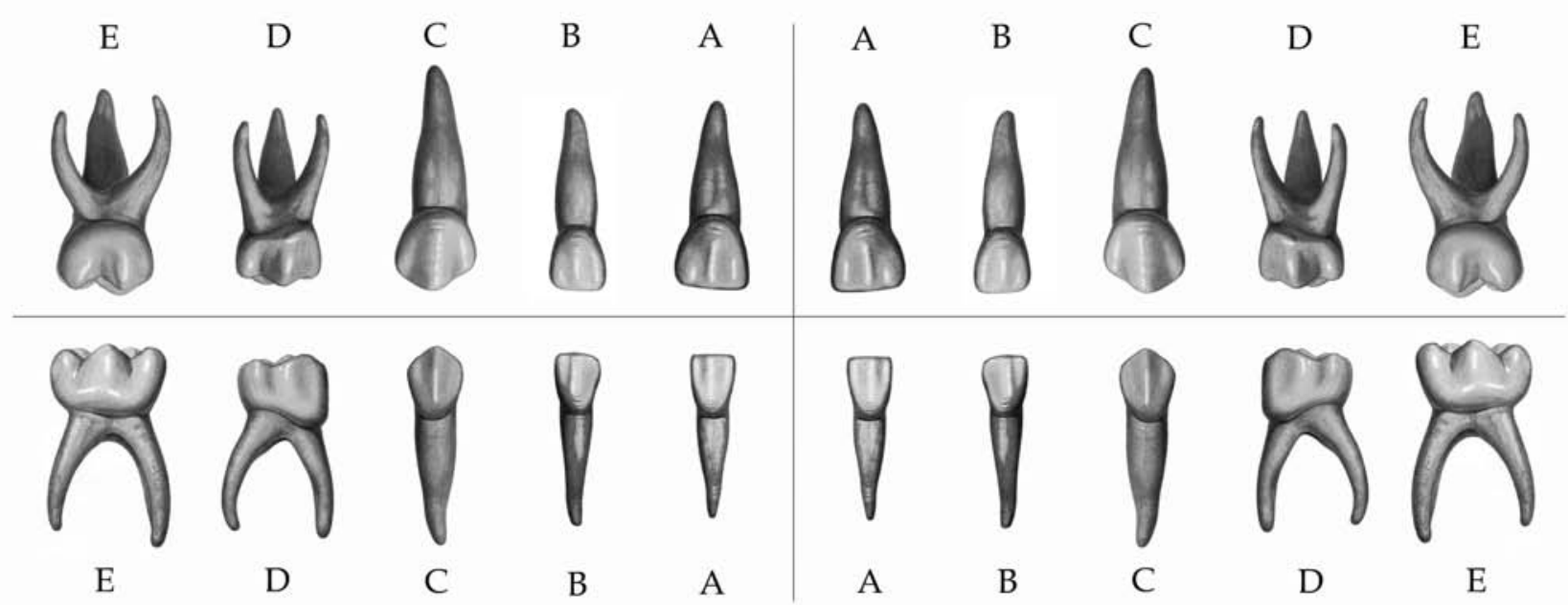

Fig. 5. The Palmer tooth designation system for the primary dentition. The five tooth types in each quadrant are denoted by letters. The quadrant is coded by using the symbol $\rfloor, L, \neg$, or $\Gamma$.

ria that, according to the Committee, are attained by this two-digit system of designating teeth:

1. Simple to understand and to teach.

2. Easy to pronounce in conversation and dictation.

3. Readily communicable in print.

4. Easy to translate into computer output.

5. Easily adapted to standard charts used in general practice.

As diagrammed in Figure 3, the first digit denotes the quadrant of the mouth, the second digit defines the tooth's normal position in the mouth, front to back.

In all of these systems, the tooth's "number" is its normal, expected position in the arch. Expectation is that there are two incisors, one canine, two premolars, and three molars in each quadrant. "Missing" teeth (due to congenital absence, impaction, extraction, etc.) are taken into account when identifying a tooth's number. When a tooth is not present, its designation has to be determined from the positions of the extant teeth. For example, permanentmandibularsecond premolarsare congenitally absent in roughly 3\% of modern humans (Stritzel et al., 1990; Larmour et al., 2005), but determination of whether it actually is the first or second premolar that is missing in a particular case depends on the clinician's differential diagnosis based on teeth that are present and related criteria. Conversely, there is no accommodation in any of these systems for supernumerary teeth; these rare events are simply written-out in the chart.

Most dentists, as with most dental anthropologists, are right handed, so quadrant 1 (maxillary right) is closest to the dentist when examining a patient and is scored first, then the upper left quadrant, then one drops down to the lower left quadrant, finishing with teeth in the lower right quadrant (Fig. 1). More formally, the quadrants are numbered "in a clockwise sequence ... starting on the upper right side" when viewing the subject from

Upper Right

Upper Left

\begin{tabular}{|c|c|c|c|c|c|c|c|c|c|c|c|c|c|c|c|}
\hline & & & $\mathrm{E}$ & $\mathrm{D}$ & $\mathrm{C}$ & B & A & A & B & C & $\mathrm{D}$ & $\mathrm{E}$ & & & \\
\hline 8 & 7 & 6 & 5 & 4 & 3 & 2 & 1 & 1 & 2 & 3 & 4 & 5 & 6 & 7 & 8 \\
\hline 8 & 7 & 6 & 5 & 4 & 3 & 2 & 1 & 1 & 2 & 3 & 4 & 5 & & 7 & 8 \\
\hline & & & & $\mathrm{D}$ & $\mathrm{C}$ & B & A & A & B & $\mathrm{C}$ & $\mathrm{D}$ & $\mathrm{E}$ & & & \\
\hline
\end{tabular}

Fig. 6. Arrangement of the permanent tooth codes in the Zsigmondy-Palmer system along with the corresponding codes (letters) for the primary teeth. Such a chart is commonly found in older dental settings (Sharma and Wadhwa, 1977), though it is being upgraded to the more easily computerized Universal or FDI systems. 


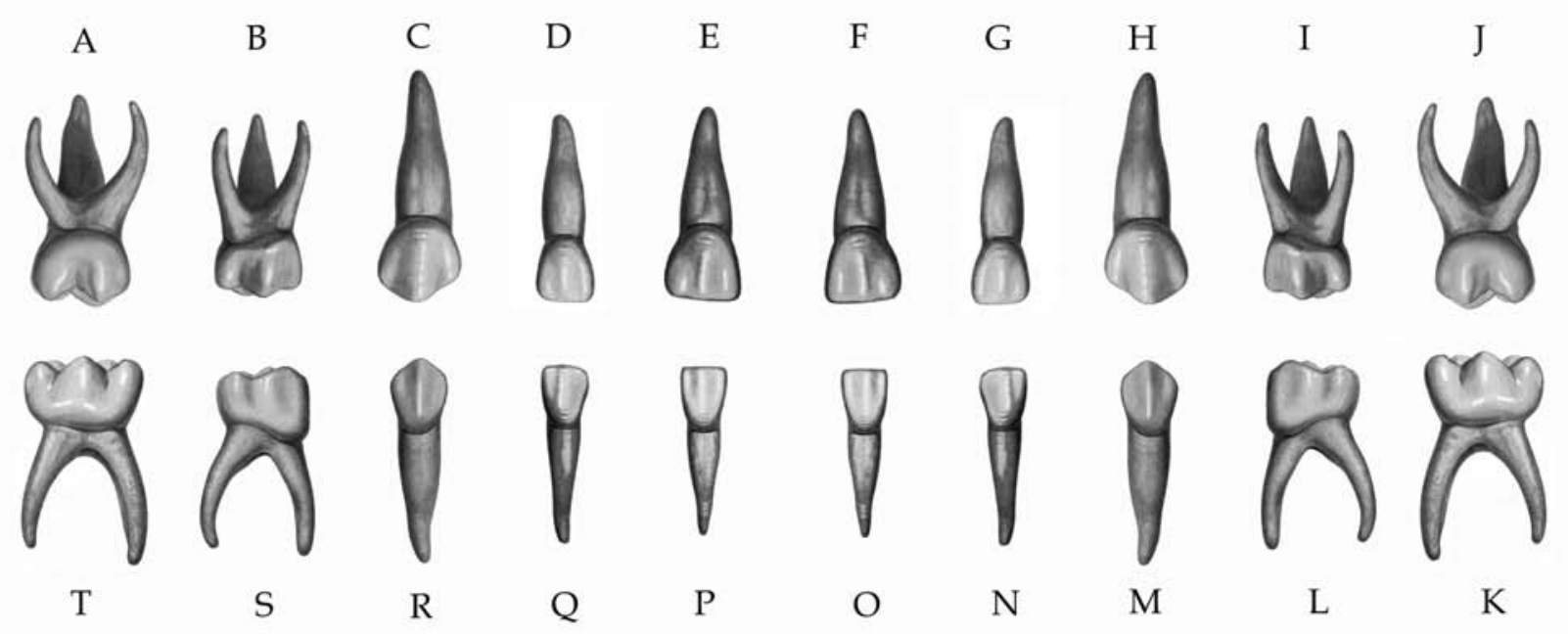

Fig. 7. The Universal system for the primary dentition, coding each tooth with a letter. As with all of these systems, the orientation refers to the patient's own right and left sides, so the patient's maxillary right quadrant is to the upper left of this diagram.

the front (Keiser-Nielsen, 1971a:105). This is to say that the upper right side (quadrant 1) is the patient's upper right side. The FDI's description also suggests how to verbalize the system, namely "The digits should be pronounced separately; thus, the permanent canines are teeth one-three, two-three, three-three, and four-three" (1971a:1034).

The FDI committee fully recognized that it was combining Zsigmondy-Palmer's tooth numbering system with the prefix number denoting the quadrant. The committee termed this a "compromise" system. The committee also pointed out that its quadrantnumbering sequence adopted the same pattern used by the Universal system, making it familiar to U.S. dentists. With this logical system, there is no ambiguity as to side, quadrant, or arcade.

\section{Universal Numbering System}

What has become the Universal system was proposed by J. Perreidt in 1882. Perreidt disliked the redundancy and potential confusion of Zsigmondy's use of tooth numbers 1 through 8 in all four quadrants. Instead, he numbered the permanent teeth 1 through 32 , starting at the upper right and continuing to the upper left, then the lower left to the lower right (Fig. 4). The main benefit

is that Zsigmondy and Palmer's angular symbol $(L$ ) is irrelevant, each tooth having its unique numerical designation.

Today, the "Universal"system of tooth-coding is an interesting misnomer, because it is only used in the United States. The ADA (American Dental Association) by a unanimous decision of its Council on Dental Care Programs adopted the Universal System of numbering teeth on April 18, 1975 (Schwartz and Stege, 1977). Numerous dentists subsequently haveeditorialized about the unnatural, illogical nature of the Universal system not to mention the unheeded complaints from fledgling dental students. The universal system is disarmingly simple in concept, just number the 32 permanent teeth from 1 through 32 (Fig. 4). The difficulty is in learning to associate specific teeth with their numbers. Once learned, of course, the system is effortless. Starting with the third molar in the upper right quadrant (tooth \#1), the teeth are numbered around the arch so the maxillary left third molar is tooth \#16. One then drops down to the mandibular left third molar (\#17) and numbers the teeth around the lower arcade, finishing with the mandibular right third molar (\#32).

There is no easy way to relate these 32 numbers to the natural, anatomic arrangement of the teeth. There is, for instance, no way to know intuitively that the second premolars are \#4,\#13,\#20 and \#29. One simply has to learn the system by rote. The compelling value of the Universal system (as with the FDI system) is the ease of computerizing the data, which is its singular selling point for automating office systems ("paperless offices"), completing insurance and other third-party reimbursement forms (certainly a financial incentive), and accelerating communication (providing that both parties understand the codes).

With both the FDI and Universal systems, each tooth has a unique identifier. This can be invaluable when irreversible procedures such as extractions or endodontic treatment are requested by one dentist from another.

\section{Primary dentition}

The primary teeth are ephemeral in that they only 


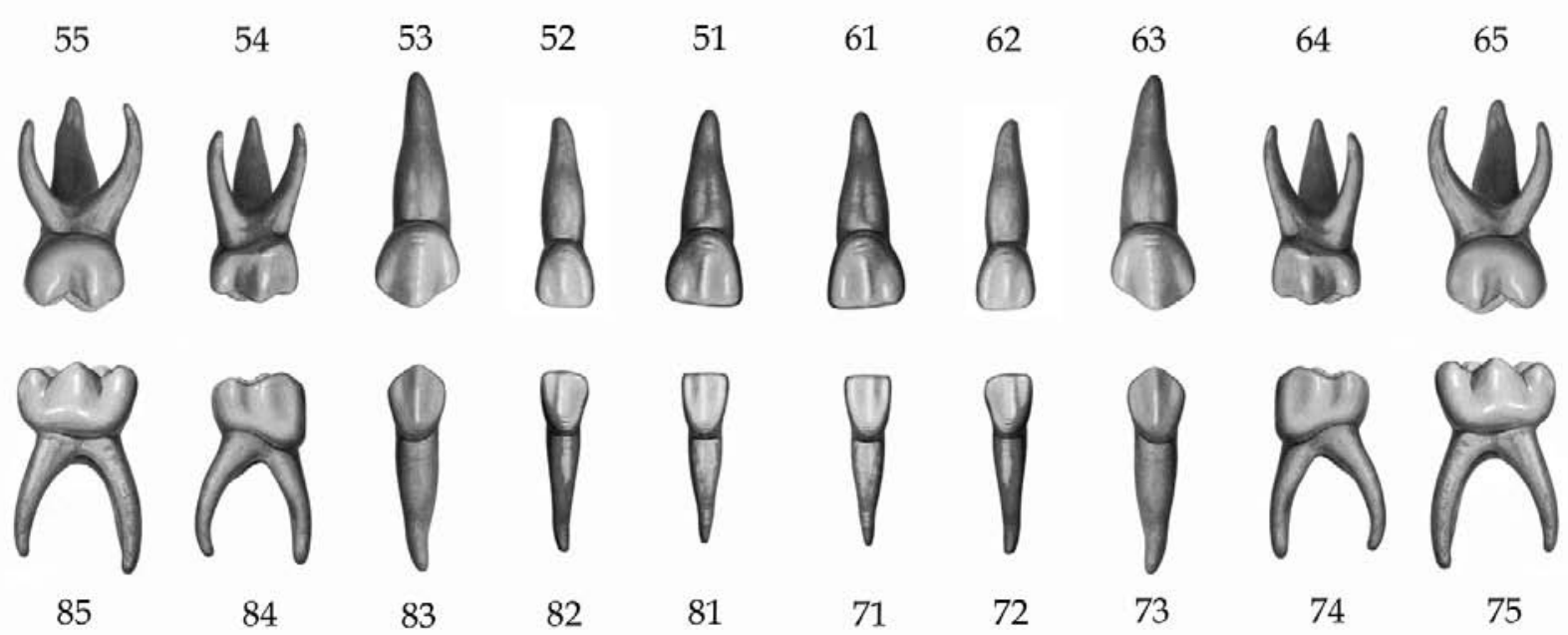

Fig. 8. The FDI system for the primary dentition. Quadrants for the primary dentition are numbered 5 through 8 . Quadrant numbers 1 through 4 are used for the permanent dentition, primarily because the dentist's attention on the permanent dentition is so much greater than with the primary dentition.

need to function for a few years before being replaced by (generally) larger and better-constructed permanent teeth with greater longevity. Typically, the first primary teeth (the incisors) erupt through the oral mucosa at 7 or 8 months of age (e.g., Tanguay et al., 1984), and the last primary teeth are exfoliated around 12 years of age, when the primary molars are replaced by the permanent premolars (e.g., Hurme, 1949; Moorrees et al., 1963). There are 20 succedaneous permanent teeth that "succeed" and replace the 20 primary teeth; the three permanent molars in each quadrant erupt distal to the primary teeth, so they are additional rather than replacement dental elements. "Primary" would seem to be the preferred term here, but common synonyms are the deciduous teeth, the baby teeth, and the milk dentition. Morphologically, the 20 primary teeth are categorized into three tooth types, incisors, canines, and molars, with the dental formula of 2:1:2 in each quadrant. Fewer clinical coding systems have been developed for the primary dentition, but there still are plenty to provide confusion for the uninitiated. The three systems analogous to those described above for the permanent dentition are presented here.

Palmer analog. Letters have commonly been used to denote the primary teeth; some systems use lower-case letters (perhaps mimicking the subadult nature of these teeth; Churchill, 1932), but capital letters are encountered more often (Fig.5). Again, the side and arcade are denoted by line segments: $\underline{B}$ is the maxillary right lateral incisor, and $\Gamma_{\mathrm{E}}$ is the mandibular left second molar.

Primary teeth have also been designated by Roman numbers $(\mathrm{I}-\mathrm{V})$, which can further confuse the novice (Churchill, 1932; Sharma and Wadhwa, 1977), particularly since still other systems have used Roman numerals to designate quadrants in the permanent dentition. A chart as in Figure 6 commonly is used in dental offices, and inspection shows that the numerals conform to Palmer's notation for the permanent teeth. while the capital letters are for the primary teeth.

Universal system. The 20 primary teeth are coded alphabetically from A through $\mathrm{T}$ (Fig. 7). There is no anatomic parallel with this system. One simply has to memorize the system by rote. If using this system infrequently, it helps to remember that $\mathrm{A}, \mathrm{J}, \mathrm{K}$ and $\mathrm{T}$ are the second molars (at the distal ends of the quadrants) and that E, F, O and P are the central incisors. Since there are only five teeth per quadrant, one can generally visualize the other tooth codes.

FDI system. So much clinical attention is spent on the permanent teeth that they are coded as quadrants 1 through 4 . The convention is to use numbers 5 through 8 to code the four primary quadrants even though they develop first (Fig. 8). This numerical oddity was the subject of considerable discussion by the FDI committee, but it was reasoned that, "mainly because deciduous teeth function for such a short time in comparison with permanent teeth that the bulk of dental data to be collected and computerized in the future would obviously concern permanent teeth" (Keiser-Nielsen, 1971a:1035).

\section{Overview}

There are two major motivations to develop a tooth-coding system. One is to conserve energy and communicate telegraphically. Writing or speaking (or typing) "the permanent mandibular right second premolar" is much more taxing than referring to this tooth as \#29 or 45, especially if teeth consume one's professional life. There is the need to be specific but also to be as concise as practical. The other, recent driving force is to computerize ever-increasing masses of data, 
and numeric codes (and their alphabetic equivalents) lend themselves to this end. The greatest emphasis has been from third-party payment systems with the need for the dentist to code the services rendered for reimbursement.

One minor spin-off of the trend toward globalization is the need for standardization - so all of the participants understand the same set of "rules" and can communicate effectively. The FDI system seems to be the solution in terms of dental-coding systems. This leaves the U.S. "Universal" system as an anachronism, but it doubtlessly will persist as a system paralleling the FDI system until the U.S. also converts to the metric system-which is moving glacially, at best. In scientific circles, though, an increasing number of dental journals is requiring its authors to use of the FDI system for tooth designations.

Only the three most common and long-lived systems are described here. Numerous others have been proposed and may be encountered (see reviews in Gustafson, 1966, and Schwartz and Stege, 1977).

\section{REFERENCES CITED}

Churchill HR. 1932. Human odontography and histology. Philadelphia: Lea \& Febiger.

Gustafson G. 1966. Forensic odontology. New York: American Elsevier Publishing Company, Inc.

Hurme VO. 1949. Ranges of normalcy in the eruption of permanent teeth. J Dent Child 16:11-15.

Keiser-NielsenS.1971a.FédérationDentaireInternationale two-digit system of designating teeth. Int Dent J 21:104-106.

Keiser-Nielsen S. 1971b. Two-digit system of designating teeth. Br Dent J 130:215-216.

Keiser-Nielsen S. 1971c. Federation Dentaire Internationale. J Amer Dent Assoc 82:1034-1035.

Kraus BS, Furr ML. 1953. Lower first premolars. I. A definition and classification of discrete morphologic traits. J Dent Res 32:554-564.

Larmour CJ, Mossey PA, Thind BS, Forgie AH, Stirrups DR. 2005. Hypodontia-a retrospective review of prevalence and etiology. Quintessence Int 36:263-270.

Le Gros Clark WE. 1959. The antecedents of man. New York: Harper \& Row.

Moorrees CFA, Fanning EA, Hunt EE Jr. 1963. Formation and resorption of three deciduous teeth in children. Am J Phys Anthropol 21:205-213.

O'Connor JT. 1983. Let's really standardize our tooth numbering system. Oper Dent 8:73-74.

Palmer C. 1891. Palmer's dental notation. Dent Cosmos 33:194-198.

Peck S, Peck L. 1993. A time for change of tooth numbering systems. J Dent Ed 57:643-647.

Parreidt J. 1882. Zählung der Zähne und Benennung der verschiedenen Zahnsorten. Zahnärzliche Mitteilungen aus der chirurgischen Universitätspoliklnik zu Leipzig, Arthur Felix, p 10-15 [cited in
Gustafson, 1966].

Schwartz S, Stege D. 1977. Tooth numbering systems: a final choice. Ann Dent 36:99-106.

Sharma PS, Wadhwa P. 1997. Evaluation of the FDI twodigit system of designating teeth. Quintessence Int 10:9-101.

Stritzel F, Symons AL, Gage JP. 1990. Agenesis of the second premolar in males and females: distribution, number and sites affected. J Clin Pediatr Dent 15:3941.

Tanguay R, Demirjian A, Thibault HW. 1984. Sexual dimorphism in the emergence of the deciduous teeth. J Dent Res 63:65-68.

de Terra M. 1905 Beitrage zu einer Odontographie den Menschenrassen. Berlin: Berlinishche Verlagsanstalt.

Todd TW. 1918. An introduction to the mammalian dentition. St Louis: CV Mosby Company.

Zsigmondy A. 1861. Grundzüge einer praktischen Methode zur raschen und genauen Vormerkung der zahnärztlichen Beobachtungen und Operationen. Deutsch Viertel Zahnhk 1:209-211.

Zsigmondy A. 1874. A practical method for rapidly noting dental observations and operations. Br J Dent Sci 17:580-582.

\section{A Brief Survey}

G. Richard Scott and I are updating the history of dental anthropology that appeared in our 1988 review article on dental anthropology in the Annual Review of Anthropology, and in the history section of our 1997 book, The Anthropology of Modern Human Teeth. We would like to add a table indicating who is teachin dental antrhopology and where the courses are being taught. The Dental Anthropology Association membership seems like the best group at which to direct such an inquiry.

If you have in the last 15 years taught a course titled dental anthropology, or an anatomical or osteological course with a significant dental anthropology component, could you please let us know. You can either e-mail me, or fill out the enclosed questionnaire. If you use the questionnaire, please return to Dr. Christy G. Turner II, 2208 N. Campo Alegre Dr., Tempe, AZ 85287-1105. In the latter case, if you have a short syllabus, we would be grateful to have a copy.

Thank you.

Christy G. Turner II

Regents' Professor Emeritus of Anthropology College of Human Evolution and Culture Change

Arizona State University

Tempe, AZ 85287-2402

E-mail: chrstygturner@aol.com 